\title{
GAD-reactive CD4+ Th1 Cells Induce Diabetes in NOD/SCID Mice
}

\author{
Dan Zekzer, ${ }^{*}$ F. Susan Wong, ${ }^{\ddagger}$ Oran Ayalon, ${ }^{\S}$ Isabelle Millet, ${ }^{*}$ Martha Altieri, ${ }^{\star}$ Shigeki Shintani, $\|$ Michele Solimena, \\ and Robert S. Sherwin* \\ $*$ Section of Endocrinology, ${ }^{\ddagger}$ Section of Immunobiology, and ${ }^{\S}$ Section of Cardiology, Yale University School of Medicine, New Haven, \\ Connecticut 06520; and ${ }^{\|}$Department of Internal Medicine, Kyoto Second Red Cross Hospital, Kyoto 602, Japan
}

\begin{abstract}
Although glutamic acid decarboxylase (GAD) has been implicated in IDDM, there is no direct evidence showing GAD-reactive $T$ cells are diabetogenic in vivo. To address this issue, 3-wk-old NOD mice received two injections of purified rat brain GAD; one mouse rapidly developed diabetes 3 wk later. Splenocytes from this mouse showed a proliferative response to purified GAD, and were used to generate a CD4 $+\mathrm{T}$ cell line, designated $5 \mathrm{~A}$, that expresses TCRs encoding $\mathrm{V} \beta 2$ and $\mathrm{V} \beta 12$. 5A T cells exhibit a MHC restricted proliferative response to purified GAD, as well as GAD65 peptide 524-543. After antigen-specific stimulation, $5 \mathrm{~A}$ T cells secrete IFN $\gamma$ and $\mathrm{TNF} \alpha / \beta$, but not IL-4. They are also cytotoxic against NOD-derived hybridoma cells (expressing I- $\mathrm{A}^{\mathrm{g} 7}$ ) that were transfected with rat GAD65, but not nontransfected hybridoma cells. Adoptive transfer of $5 \mathrm{~A}$ cells into NOD/SCID mice produced insulitis in all mice. Diabetes occurred in $83 \%$ of the mice. We conclude that GAD injection in young NOD mice may, in some cases, provoke diabetes due to the activation of diabetogenic $T$ cells reactive to GAD65 peptides. Our data provide direct evidence that GAD65 autoimmunity may be a critical event in the pathogenesis of IDDM. (J. Clin. Invest. 1998. 101:6873.) Key words: immunology • autoimmunity • cytotoxicity • cytokine $\cdot$ animal model
\end{abstract}

\section{Introduction}

The destruction of insulin-producing pancreatic $\beta$ cells, leading to insulin-dependent diabetes mellitus (IDDM), ${ }^{1}$ is a highly selective process. While autoimmunity has been implicated as the pathogenic mechanism of IDDM, the trigger that initiates the autoimmune process and the autoantigen recognized by islet-reactive diabetogenic $\mathrm{T}$ cells is as of yet unknown. Adoptive transfer of NOD mouse-derived islet reactive polyclonal cells or cloned $\mathrm{T}$ cell lines (1-3) reactive to

Address correspondence to Robert Sherwin, M.D., Department of Internal Medicine, Yale University School of Medicine, Box 208020, FMP 101, New Haven, CT 06520-8020. Phone: 203-785-4183; FAX: 203-737-5558; E-mail: robert_sherwin@qm.yale.edu

Received for publication 19 February 1997 and accepted in revised form 10 June 1997.

1. Abbreviations used in this paper: GAD, glutamic acid decarboxylase; IDDM, insulin-dependent diabetes mellitus.

J. Clin. Invest.

(C) The American Society for Clinical Investigation, Inc. 0021-9738/98/01/0068/06 \$2.00

Volume 101, Number 1, January 1998, 68-73

http://www.jci.org known and unknown beta cell antigens (4-8) into irradiated NOD or NOD/SCID mice, rapidly produces diabetes. Although generally both CD4 and CD8 T cells are needed for disease transfer, some T cell clones that express CD4 (7) or CD8 (8) can transfer diabetes to NOD/SCID mice.

A candidate target beta cell autoantigen for diabetogenic $\mathrm{T}$ cells is glutamic acid decarboxylase (GAD). GAD is represented by two isoforms consisting of $65 \mathrm{kD}$ (GAD65) and $67 \mathrm{kD}$ (GAD67), respectively. The two proteins are very similar to each other, and are found predominantly in the brain and pancreas (9). Both GAD isoforms, but primarily GAD65, are the targets of autoimmunity in IDDM. Autoantibodies and T cells reactive to GAD65 are found in most newly diagnosed patients with diabetes $(10,11)$. $\mathrm{T}$ cells from the spleens of young nondiabetic NOD mice demonstrate an early proliferative response to GAD65 that precedes those of other beta cell antigens tested $(12,13)$. In particular, two peptides (509-528 and 524-543) near the COOH-terminus of GAD65 have been reported to trigger the earliest response; proliferation of splenocytes is seen in 4-wk-old NOD mice (12). The importance of GAD65 is also supported by data showing that NOD mice are tolerized to GAD65 administered intravenously or intrathymically soon after weaning, and both insulitis and diabetes are prevented $(12,13)$. Similar protection has been recently reported using nasal administration of a combination of GAD65 peptides, perhaps by altering Th1/Th2 cell balance (14). Data linking GAD65 with IDDM has thus far, however, been primarily indirect; there has been no evidence to date that GAD65-specific T cells can directly produce $\beta$ cell injury and/ or diabetes. To address this issue, we report here on a CD4+ oligoclonal $\mathrm{T}$ cell line that recognizes GAD65 as its antigen (specifically, GAD65 peptide 524-543) and is able to adoptively transfer diabetes to NOD/SCID mice.

\section{Methods}

Purification of rat brain $G A D$. An antigenic mixture containing both GAD65 and GAD67 was purified from rat brain by affinity chromatography with GAD6 monoclonal antibody, as described in detail by Butler et al. (15). Although GAD6 only recognizes GAD65, affinity chromatography with this antibody results in the purification of both native isoforms because of their association as heterodimers (16). In brief, $25 \mathrm{~g}$ of rat brain was homogenized in a potassium phosphate buffer, $\mathrm{pH}$ 7.5. The homogenate was centrifuged at 130,000 $\mathrm{g}$ for $1 \mathrm{~h}$ at $4^{\circ} \mathrm{C}$, and the supernatant was loaded onto an affinity column prepared by conjugating the GAD6 antibody to Affi-gel 10 (Bio-Rad Laboratories, Richmond, CA) and allowed to flow through at a slow, steady rate. The column was then washed, and GAD was eluted with elution buffer $(0.5 \mathrm{M}$ potassium phosphate buffer containing $.01 \mathrm{M}$ diethylamine and .02 M glutamate, $\mathrm{pH} 11$ ) and then dialyzed with water for $3 \mathrm{~d}$. The GAD preparation was concentrated by lyophilization, and was then dissolved in $1 \times$ PBS. The amount of protein was estimated using BSA protein assay (Bio-Rad Laboratories, Hercules, CA) and then analyzed by electrophoresis on an $8 \%$ denaturing acrylamide gel. The purity of the preparation was checked by silver staining of the gel, and the identity of GAD was confirmed by Western 
blotting with the rabbit antiserum no. 7673 , which recognizes both GAD isoforms (15).

Mice. Female NOD/Caj mice were used to generate GAD-reactive T cells. Female 6-7-wk-old NOD/SCID mice (The Jackson Laboratory, Bar Harbor, ME) were used as recipients in adoptive transfer experiments. Mice were housed in specific pathogen-free conditions with $12 \mathrm{~h}$ light-dark cycles. In this colony, female NOD mice develop diabetes from $12 \mathrm{wk}$ of age, reaching an incidence of $90 \%$ by $24 \mathrm{wk}$, whereas NOD/SCID mice never develop insulitis or diabetes. B10.GD mice, used as controls, were originally purchased from the Jackson Laboratory.

Generation and propagation of $G A D$-reactive $T$ cells. The antigenic mixture of affinity-purified rat brain GAD65 and GAD67 (25 $\mu \mathrm{g})$ was injected intravenously into three 3 -wk-old NOD recipients, followed a week later by an injection of the GAD preparation $(100 \mu \mathrm{g})$ intraperitoneally. This protocol was adapted from that previously used by Matsuba et al. (17) to generate GAD-reactive T cells in NOD mice. In one mouse, diabetes unexpectedly developed at $6 \mathrm{wk}$ of age. This mouse was killed, and its spleen cells were used as a source of T cells for the experiments to follow. Cells were expanded in culture in Click's medium supplemented with $5 \%$ FCS, penicillin $(200 \mu \mathrm{g} / \mathrm{ml})$, streptomycin $(200 \mu \mathrm{g} / \mathrm{ml})$, and $5 \mathrm{U} / \mathrm{ml}$ of IL2 (EL4 supernatant) at $37^{\circ} \mathrm{C}$ and $5 \% \mathrm{CO}_{2}$. The cells were stimulated with the purified GAD preparation together with irradiated NOD spleen cells as antigenpresenting cells every 2 wk. After 6 wk in bulk culture, the cells showed a proliferative response to purified GAD, and as a result, were cloned by limiting dilution. Among the oligoclonal $\mathrm{T}$ cell lines obtained, one $\mathrm{T}$ cell line, designated $5 \mathrm{~A}$, was studied further.

Generation of GAD transfectant cells. Rat GAD65 cDNA (18) was subcloned into $\mathrm{pRc} / \mathrm{RSV}$ expression vector (Invitrogen Corp., Carlsbad, CA) and transfected into a hybridoma designated NXA (kindly provided by Dr. Charles A. Janeway Jr, New Haven, CT) by electroporation. The hybridoma, NXA, generated by fusion of the B cell lymphoma A20 and B lymphocytes from NOD mice, expresses the NOD class I molecules $\mathrm{H}-2 \mathrm{~K}^{\mathrm{d}}$ and $\mathrm{H}-2 \mathrm{D}^{\mathrm{b}}$ as well as NOD class II $\mathrm{I}^{-\mathrm{A}^{\mathrm{g} 7}}$ (S. Wong, unpublished data). The GAD65 transfectant designated E8 was cloned, and expression of GAD65 was demonstrated by Western blot analysis.

Thymidine incorporation proliferation assays. $10^{4} 5 \mathrm{~A}$ T cells were incubated with $10^{5}$ irradiated NOD splenocytes with or without 10 $\mu \mathrm{g} / \mathrm{ml}$ purified GAD for $72 \mathrm{~h}$. Thereafter, the cultures were pulsed with $1 \mu \mathrm{Ci}$ of $\left[{ }^{3} \mathrm{H}\right]$ thymidine (New England Nuclear, Boston, MA) and harvested $16 \mathrm{~h}$ later to measure incorporation of radioactivity. In addition, proliferation assays were performed using the hybridoma transfected with GAD65, E8, using the nontransfected hybridoma NXA as a control. The hybridomas were pretreated with $500 \mu \mathrm{g} / \mathrm{ml}$ Mitomycin C $\left(10^{7}\right.$ cells $\left./ \mathrm{ml}\right)$ for $3 \mathrm{~h}$. To further define antigen specificity, similar proliferation assays were performed using mouse GAD65 peptides 509-528, 524-543, and as a control, a GAD65 peptide with reverse sequence (543-524), synthesized in the Keck Biotechnology facility (Yale University, New Haven, CT).

$M H C$ restriction assays. MHC restriction of the T cells was tested in proliferation assays using purified GAD as antigen, together with NOD antigen-presenting cells and monoclonal antibodies (at a concentration of $10 \mu \mathrm{g} / \mathrm{ml}$ ) directed at $\mathrm{IA}^{\mathrm{g} 7}(10.2 .16)$ as well as $\mathrm{H}-2 \mathrm{~K}^{\mathrm{d}}$ (HB159) and H-2D ${ }^{\mathrm{b}}$ (HB51), which were kindly provided by Dr. C.A. Janeway Jr.. Rat IgG (Pierce Chemical Co., Rockford, IL) was used as a control. MHC restriction was further tested by performing a proliferation assay using $10^{5}$ irradiated B10.GD splenocytes as antigen-presenting cells, and purified GAD as antigen. B10.GD mice $\left(\mathrm{K}^{\mathrm{d}} \mathrm{D}^{\mathrm{b}} \mathrm{I}-\mathrm{A}^{\mathrm{d}}\right)$ match NOD $\left(\mathrm{K}^{\mathrm{d}} \mathrm{D}^{\mathrm{b}} \mathrm{I}-\mathrm{A}^{\mathrm{g} 7}\right)$ mice at the MHC Class I, but not the MHC Class II locus. MHC restriction was tested in a similar manner using the above antibodies at a concentration of $3 \mu \mathrm{g} / \mathrm{ml}$ when the GAD65 transfected hybridoma E8 was used as the antigen presenting cell.

Flow cytometry. Cells were stained with the following monoclonal antibodies: FITC-conjugated anti-CD4 and anti-CD8 (Gibco BRL, Gaithersburg, MD), PE-conjugated anti- $\alpha \beta T C R$, and FITC-conjugated anti-V $\beta$ 2, 3, 5, 6, 7, 8, 9, 10, 11, 12, 14, 17 (PharMingen, San
Diego, CA). The cells were also stained with unconjugated anti- $\alpha 4$ integrin (R1-2), anti-ICAM-1 (YN1/1.7.4), and anti-LFA-1(M17/5.2), kindly provided by Dr. C.A. Janeway Jr. FITC-conjugated anti-rat IgG antibody (Hyclone, Logan, UT) was used with the unconjugated primary antibodies. The cells were incubated with the directly conjugated antibodies for $30 \mathrm{~min}$ at $4^{\circ} \mathrm{C}$ in PBS containing $1 \% \mathrm{FCS}$ and $0.1 \%$ sodium azide, and were then washed. When unconjugated primary antibodies were used (after the cells were washed) there was a further incubation with the secondary antibody using the same conditions. Stained cells were analyzed using a FACS SCAN IV (Becton Dickinson, Mountain View, CA).

Cytokine profile. Total cellular RNA was prepared from $2 \times 10^{6}$ $\mathrm{T}$ cells using RNAzol B (Biotecx Laboratories, Inc., Houston, TX) according to the manufacturer's instructions. RNA was then primed at $55^{\circ} \mathrm{C}$ using oligo $\mathrm{dT}_{12-18}$ (Gibco BRL) and reverse transcribed with $300 \mathrm{U}$ of Maloney Murine Leukemia Virus reverse transcriptase (Gibco Laboratories, Grand Island, NY) in a final volume of $40 \mu \mathrm{l}$ containing $0.55 \mu \mathrm{l}$ RNAsin (Promega Corp., Madison, WI), $4 \mu \mathrm{l}$ DTT (Gibco BRL), $8 \mu \mathrm{l} 5 \times$ buffer (Tris $\mathrm{HCl}, \mathrm{KCl}, \mathrm{MgCl}_{2}$ ) and $25 \mu \mathrm{mol}$ dNTP (Pharmacia LKB Biotechnology Inc., Piscataway, NJ). The reaction was terminated by heating to $70^{\circ} \mathrm{C}$ for $5 \mathrm{~min}$, and the final volume was adjusted to $100 \mu \mathrm{l}$. $2 \mu \mathrm{l}$ of cDNA was then used for subsequent PCRs.

PCR reactions were carried out using $1 \mathrm{U}$ Taq polymerase (Promega Corp.) in a reaction containing $2.5 \mu \mathrm{l} 10 \times \mathrm{PCR}$ buffer $(500$ $\mathrm{mM} \mathrm{KCl}, 100 \mathrm{mM}$ Tris- $\mathrm{HCl} \mathrm{pH} 9.0$ at $25^{\circ} \mathrm{C}, 1 \%$ Triton X-100), $1.5 \mathrm{mM}$ $\mathrm{MgCl}_{2}, 0.25 \mu \mathrm{dNTP}$ mix $(25 \mathrm{mM}), 25 \mathrm{ng}$ of each primer, and $2 \mu \mathrm{l}$ cDNA in a final volume of $25 \mu \mathrm{l}$. IFN- $\gamma$, IL-4, TNF $\beta$, and HPRT (as a control) were synthesized according to Reiner et al. (19) with modifications. PCR reaction conditions used for all cytokine messages were as follows: denaturation at $94^{\circ} \mathrm{C}$ for $40 \mathrm{~s}$, annealing at $55^{\circ} \mathrm{C}$ for $1 \mathrm{~min}$, and extension at $72^{\circ} \mathrm{C}$ for $40 \mathrm{~s}$ for 35 cycles followed by an extension at $72^{\circ} \mathrm{C}$ for $7 \mathrm{~min}$.

Measurement of cytokines. Supernatant derived from the $\mathrm{T}$ cell line $5 \mathrm{~A}$ was collected $72 \mathrm{~h}$ after stimulation with purified GAD or GAD65 peptide 524-543 for measurement of IL-4 and IFN $\gamma$ and $\mathrm{TNF} \alpha / \beta$ production. IL-4 and IFN $\gamma$ concentrations were measured by ELISA using monoclonal antibodies specific for IL-4 or IFN $\gamma$, respectively (PharMingen). Recombinant IL-4 and IFN $\gamma$ (Gibco Laboratories) were used for generation of standard curves. $\mathrm{TNF} \alpha / \beta$ activity was measured based on its cytotoxic effect on Wehi-164 fibrosarcoma cells, as previously described (20).

Cytotoxic activity. The cytotoxic activity of the 5A T cells was tested against the GAD65 transfectant E8, and the NXA hybridoma cells (as a control), in calcein-AM retention assays, as described previously $(21,22)$. In brief, target cells were washed twice with PBS and labeled with $3 \mu \mathrm{M}$ calcein-AM (Molecular Probes Inc., Eugene, OR) in serum and phenol red-free medium (Gibco BRL) for $40 \mathrm{~min}$ at $37^{\circ} \mathrm{C}$, washed twice with PBS, and plated into U-bottomed microtiter plates at a concentration of $2 \times 10^{4}$ cells per well. Labeling efficiency was initially assessed using a Cytofluor II fluorescence plate reader (PerSeptive Biosystems, Framingham, MA). Effector cells were added in effector/target ratios of 80:1, 40:1, and 1:1 in quadruplicate. Phenol red-free medium was added to a six-well set of target cells for estimation of retention of calcein-AM in medium alone. Maximal lysis was determined by solubilizing six wells of target cells in lysis buffer $(50 \mathrm{mM}$ sodium borate, $0.1 \%$ Triton $\mathrm{X}-100, \mathrm{pH} 9.0$ ). After $4 \mathrm{~h}$ incubation at $37^{\circ} \mathrm{C}$, the assays were terminated by washing the plates twice, and the remaining fluorescence was read. Percent specific cytotoxicity was calculated as follows: $\%$ cytotoxicity $=([$ retention experimental well - retention maximal lysis]/[retention in medium - retention maximal lysis] $) \times 100$. Retention values were calculated by normalizing measured fluorescence with initial labeling efficiency of the same well.

In vivo adoptive transfer. Female, 7-wk-old NOD/SCID mice were injected intravenously with $10^{7} 5 \mathrm{~A}$ T cells $(n=12)$. As negative controls, NOD/SCID mice were injected with normal saline $(n=4)$ or with a Th1-type cloned $\mathrm{T}$ cell line specific for ovalbumin OVA3E3 
$(n=3)$. The latter was done as a separate experiment. The animals were monitored for glycosuria using Diastix (Bayer, Elkhart, IN) and diabetes was confirmed by a random blood glucose measurement of $>13.9 \mathrm{mmol}(250 \mathrm{mg} / \mathrm{dl})$. The animals injected with $5 \mathrm{~A} \mathrm{~T}$ cells were killed at the time they became diabetic, which ranged from 4-11 wk after injection. Two mice were killed 4 and $6 \mathrm{wk}$ after injection, at which time diabetes was not present.

Histology. The pancreas from diabetic 5A-injected NOD/SCID mice and control animals were either fixed in $10 \%$ buffered formalin, paraffin-embedded and stained with haematoxylin and eosin ( $\mathrm{H} \& \mathrm{E})$, or processed for immunocytochemistry, as previously described (23). After $24 \mathrm{~h}$, the tissue was sucrose-infused, embedded in Tissue Tek OCT (Bayer), and frozen in isopentane. The H \& E sections were examined microscopically for the presence of insulitis. For immunohistochemistry, $12-\mu \mathrm{m}$-thick frozen sections were double-immunolabeled with a rat anti-CD4 or anti-CD8 antibody conjugated to FITC (PharMingen) and a rabbit antiserum directed against the islet antigen ICA512 followed by L-Rhodamine-conjugated goat-anti rabbit IgG (Boehringer Mannheim, Indianapolis, IN). These sections were then examined using confocal microscopy, as previously described (24).

\section{Results}

The specificity and $\mathrm{MHC}$ restriction of the $\mathrm{T}$ cell line $5 \mathrm{~A}$, isolated from the splenocytes of a young mouse that developed diabetes after immunization with affinity purified GAD, is shown in Fig. 1. 5A T cells proliferate in response to purified GAD, whereas there was a minimal response to NOD APCs alone (Fig. $1 \mathrm{~A}$ ). The clone exhibits a similar proliferative response to GAD65 peptide 524-543, but not to a peptide of the reverse sequence (Fig. $1 A$ ) or to GAD65 peptide 509-528 (data not shown). The proliferative response is restricted to $\mathrm{I}-\mathrm{A}^{\mathrm{g} 7}$, as the cells do not proliferate in the presence of a monoclonal antibody to $\mathrm{I}-\mathrm{A}^{\mathrm{g} 7}$, whereas antibodies to $\mathrm{H}-2 \mathrm{~K}^{\mathrm{d}}$ and $\mathrm{H}-2 \mathrm{D}^{\mathrm{b}}$ have no effect (Fig. $1 \mathrm{~B}$ ). This MHC restriction was confirmed by the lack of response when splenocytes from B10.GD mice (matched with NOD MHC class I but not the MHC class II locus) are used to present GAD (Fig. $1 B$ ). In addition, the $5 \mathrm{~A} \mathrm{~T}$ cells proliferate to the GAD65-expressing transfectant, E8, but not to the control hybridoma, NXA. This response is also $\mathrm{IA}^{\mathrm{g} 7}$ restricted, as it is blocked by the monoclonal antibody to $\mathrm{IA}^{\mathrm{g} 7}$, but not by antibodies to $\mathrm{H}-2 \mathrm{~K}^{\mathrm{d}}$ and $\mathrm{H}-2 \mathrm{D}^{\mathrm{b}}$ (Fig. $1 C$ ). The $5 \mathrm{~A}$ $\mathrm{T}$ cells are CD4+CD8- and express predominantly $\mathrm{V} \beta 2$ and V $\beta 12$ as shown by flow cytometry. Furthermore, the cells express the adhesion molecules $\alpha 4$ integrin, LFA-1, and ICAM-1 (data not shown).

The cytokine profile of $5 \mathrm{~A}$ T cells, as determined by RTPCR, shows gene expression of IFN $\gamma$, IL4, and TNF 3 . In supernatants from $5 \mathrm{~A}$ cells, however, there was a progressive increase in the levels of IFN $\gamma$, whereas IL4 remained at a low level after in vitro stimulation with purified GAD (Fig. 2). Furthermore, GAD stimulation enhanced the secretion of $\mathrm{TNF} \alpha / \beta$ (data not shown). This finding may reflect the presence of a few Th 2 cells in the T cell line. The high level of IFN $\gamma$ indicates that the cells are predominantly of Th1 type.

Cytotoxic activity of the 5A T cells was tested in vitro against the transfectant expressing GAD65. As shown in Fig. 3, 5A $\mathrm{T}$ cells have a significant cytolytic effect on the GAD transfectant, E8, as compared to the parent hybridoma, NXA, in calcein-AM retention assays $(P<0.01$, ANOVA).

Strikingly, after adoptive transfer of $5 \mathrm{~A}$ T cells into female NOD/SCID mice, diabetes occurred in 10 of 12 mice (mean blood glucose in the diabetic mice was $402 \pm 36 \mathrm{mg} / \mathrm{dl}$ ) (Fig. 4). This occurred in the absence of any other cotransferred cells. None of the mice injected with saline or the control ovalbumin-reactive T cells developed insulitis or diabetes (Figs. 4 and 5). Histologic analysis of the pancreatic sections for the mice given GAD-reactive $T$ cells demonstrated intense insulitis and islet cell destruction in each of the diabetic mice (Fig. $5 C$ ), and
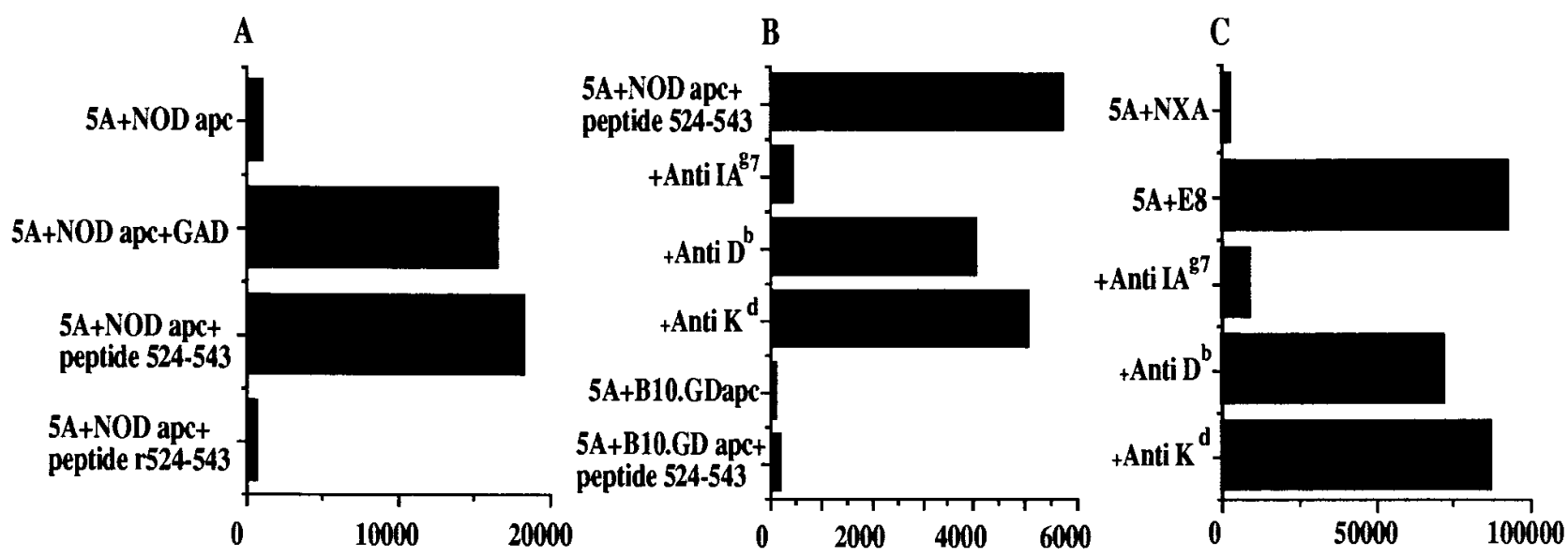

\section{C.P.M}

Figure 1. Thymidine incorporation proliferation assays. (A) 5A T cells proliferate in response to the purified GAD preparation and GAD65 peptide 524-543, but not to a control peptide of reverse sequence to 524-543 (r524-543). (B) The 5A T cells show MHC restriction to I-A ${ }^{\mathrm{g} 7}$, as shown by inhibition of the proliferative response to peptide 524-543, in the presence of an antibody to I-A $\mathrm{A}^{\mathrm{g} 7}$, but not in the presence of antibodies to the NOD MHC class I molecules $\mathrm{K}^{\mathrm{d}}$ and $\mathrm{D}^{\mathrm{b}}$. Additionally, the $5 \mathrm{~A}$ T cells do not respond if B10.GD antigen-presenting cells are used (K $\mathrm{K}^{\mathrm{d}-}$ $\left.\mathrm{D}^{\mathrm{b}} \mathrm{I}-\mathrm{A}^{\mathrm{d}}\right) .(C) 5 \mathrm{~A}$ T cells proliferate to the GAD65 transfectant E8, but not to the nontransfected control hybridoma NXA. The proliferation is also inhibited in the presence of antibody to $\mathrm{I}-\mathrm{A}^{\mathrm{g} 7}$, but not in the presence of antibodies to NOD MHC class I molecules $\mathrm{K}^{\mathrm{d}}$ and $\mathrm{D}^{\mathrm{b}}$. Proliferation of $5 \mathrm{~A}$ alone was $<400 \mathrm{cpm}$, whereas NXA and E8 alone were $<15,000 \mathrm{cpm}$. The data in Fig. $1 A-C$ were generated in separate experiments. Each value is the mean of triplicate determinations. 


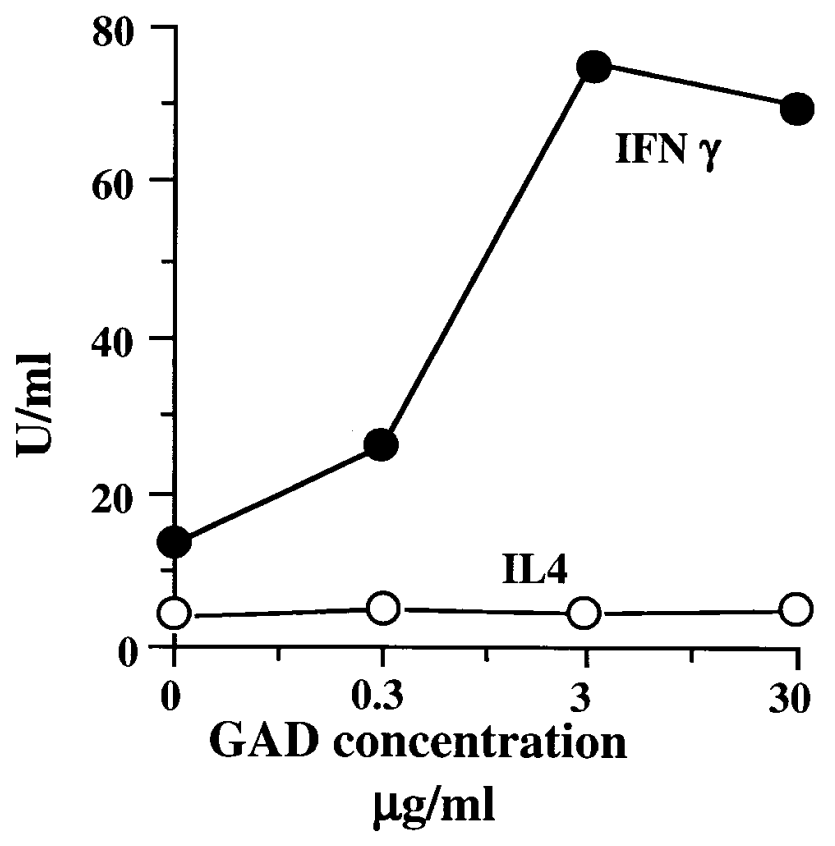

Figure 2. Production of IFN $\gamma$ and IL4 in culture supernatant on stimulation of $5 \mathrm{~A}$ T cells with NOD antigen-presenting cells and increasing GAD concentrations, measured by ELISA.

less severe insulitis in the two nondiabetic mice (data not shown). Immunocytochemistry was consistent with the presence of the 5A $\mathrm{T}$ cell line, as the cells infiltrating the islet stained with anti-CD4 (Fig. 5 D), but not anti-CD8 (data not shown).

\section{Discussion}

GAD, primarily GAD65, has been shown to provoke an early immune response in NOD mice $(12,13)$, and several reports

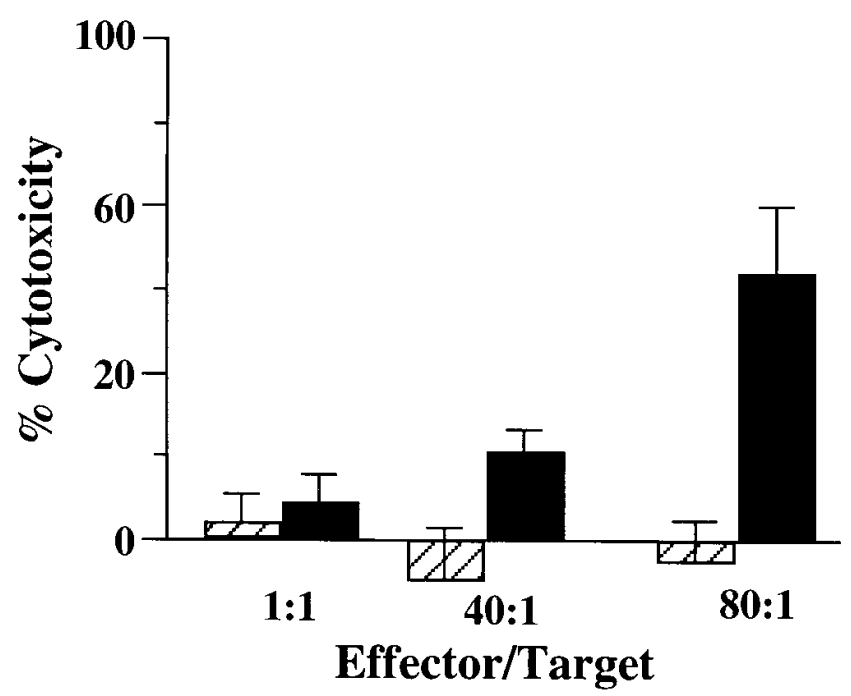

Figure 3. Cytolytic effect of 5A T cells on the GAD65 transfectant, $\mathrm{E} 8$, and the control hybridoma, NXA, as measured by calcein-AM retention assays. $\%$ cytotoxicity represents mean \pm standard error of quadruplicate wells. Black bars, GAD 65 transfectant E8; striped bars, nontransfected hybridoma NXA.

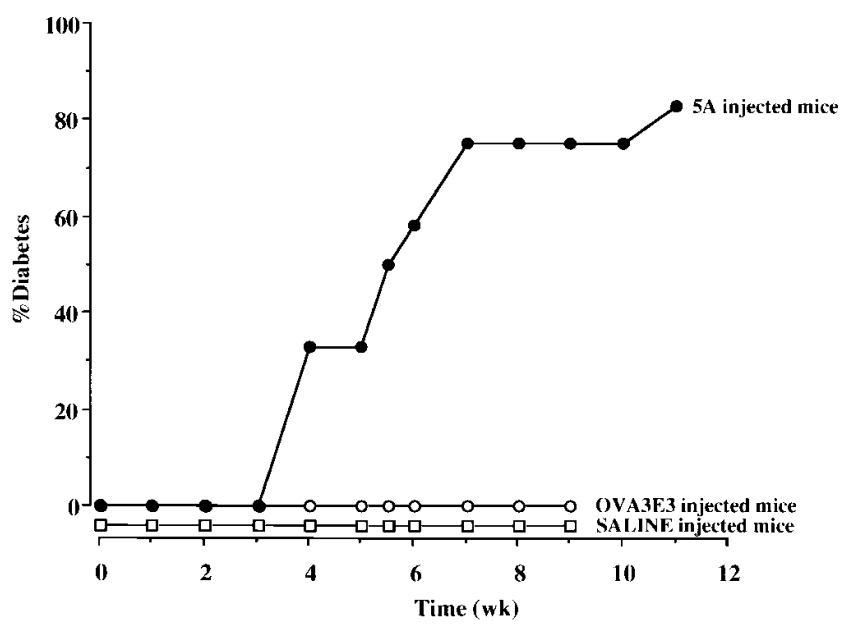

Figure 4. Cumulative incidence of diabetes in NOD/SCID mice after adoptive transfer with 5A T cells alone into NOD/SCID mice $(n=$ 12 , closed circles). As controls, OVA3E3 cells ( $n=3$, open squares) or saline ( $n=4$, open circles) were injected into NOD/SCID mice.

have documented the ability of GAD65 or GAD65 peptides delivered by a variety of routes to tolerize mice and to prevent the onset of diabetes $(12-14,25)$. In this report, the injection of an antigenic mixture containing native GAD65 and GAD67, instead of preventing diabetes, actually accelerated the onset of the disease in one of three mice. Although the difference in outcome may be explained by differences in the composition, doses, and routes of administration of GAD, the current observations raise a note of caution. Similar issues have been raised by a recent report suggesting that autoimmune diabetes could be induced by oral administration of autoantigen by eliciting a cytotoxic $\mathrm{T}$ cell response (26). The GAD-reactive T cells that we isolated from a mouse immunized with GAD are highly efficient in causing diabetes. It is of interest that the fine specificity of these $\mathrm{T}$ cells has been identified to be GAD65 peptide 524-543, an epitope that has been previously identified to be dominant in the early phases of disease (12). This suggests that GAD65-reactive cells, present in young NOD mice, and which respond to this epitope of GAD65, may well be important in the early initiating phases of insulitis. The rapid onset of diabetes after immunization with purified native GAD might have occurred as a result of the activation and expansion of such a population of $\mathrm{T}$ cells with diabetogenic potential, which are then able to accelerate disease expression. It is noteworthy that these CD4+ GAD-reactive T cells are able to induce diabetes in NOD/SCID mice without cotransferred CD8 T cells.

The mechanism by which CD4 T cells are able to cause diabetes in the absence of host or added CD8 T cells or B cells is uncertain. Previous studies have documented that other CD4+ islet-reactive $\mathrm{T}$ cells are able to adoptively transfer disease (7) in the absence of host lymphocytes. It seems unlikely, however, that the mechanism is antigen-specific, as murine islet $\beta$ cells lack MHC class II molecules necessary for antigen presentation to CD4 T cells $(27,28)$. Recently, it has been shown that CD4 $\mathrm{T}$ cells can induce apoptosis leading to accelerated diabetes (29), and since our GAD65-reactive T cells do secrete $\mathrm{TNF} \alpha / \beta$ and express Fas Ligand and not perforin mRNA (un- 

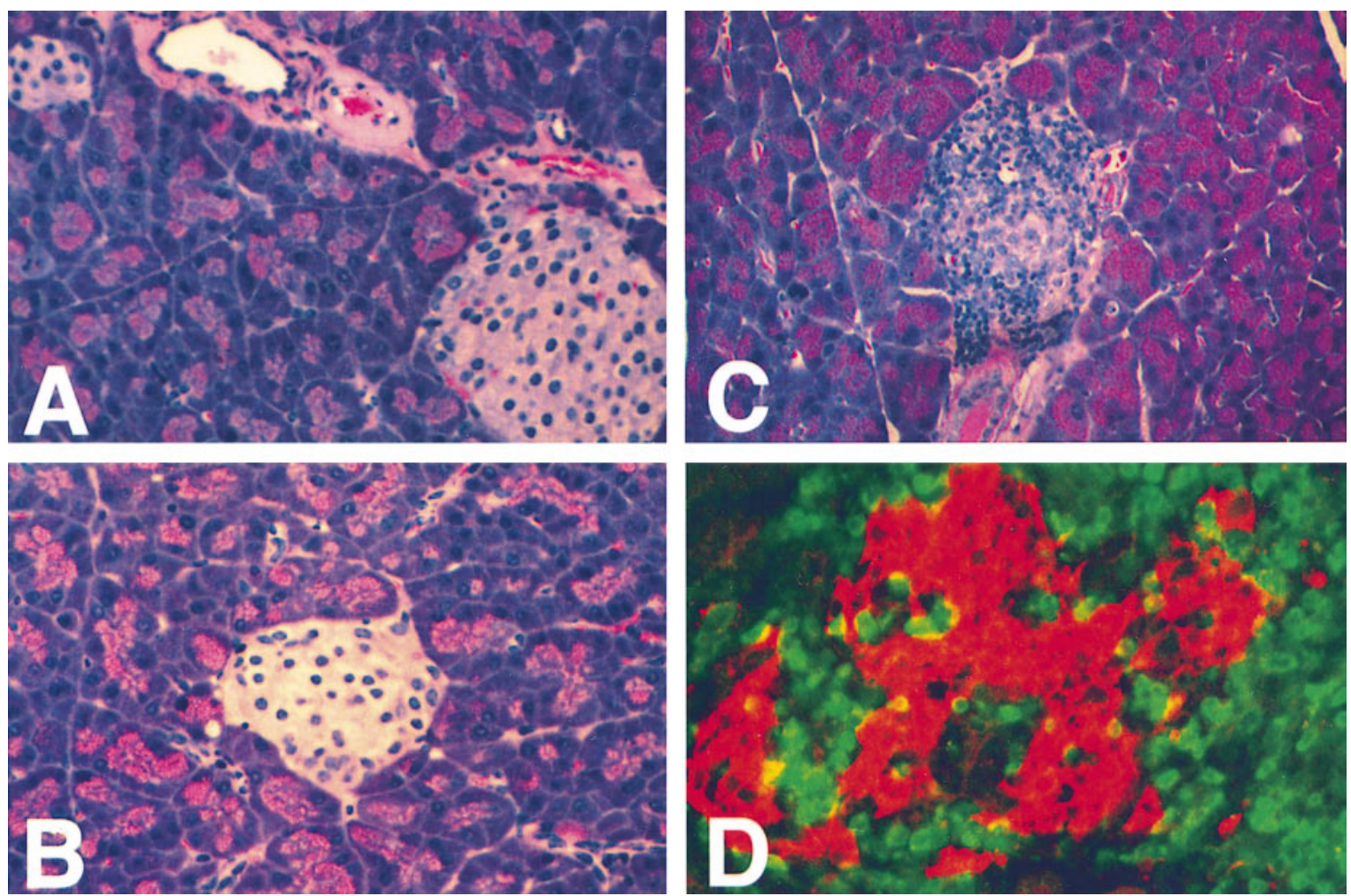

Figure 5. Histology of representative pancreatic sections from mice after adoptive transfer. No insulitis is seen in mice after transfer of ovalbumin specific OVA3E3 T cells $(A)$ or saline $(B)$. Insulitis is seen in the islets of the mice that became diabetic after adoptive transfer of $5 \mathrm{~A}$ T cells (C). $A-C$ are stained with $\mathrm{H} \& \mathrm{E}$. Confocal microscopy in a prediabetic mouse is shown in $D$. The $5 \mathrm{~A}$ T cells are shown in green, stained with anti-CD4 antibody conjugated to FITC, while pancreatic islet cells are shown in red, stained with rabbit anti-ICA512 antibody followed by L-Rhodamine-conjugated goat-anti rabbit IgG.

published data), it is possible that induction of apoptosis through Fas/Fas ligand interactions or TNF $\alpha$ cells/TNF $\alpha$ receptor pathway is the mechanism by which 5A cells damage islet $\beta$ cells and cause diabetes. Certainly, the $5 \mathrm{~A}$ T cells produce Th1 cytokines that upregulate Fas on islets (30).

The current data provide support for the view that GAD65 autoimmunity has a key role in the pathogenesis of IDDM. Although there is strong evidence indicating that GAD65 might be a critical autoantigen for the cellular immune response leading to diabetes, there has been a paucity of data regarding the function of GAD-reactive T lymphocytes; specifically, whether they are capable of promoting diabetes. Several distinct cloned CD4+ $\mathrm{T}$ cell lines reactive to recombinant GAD65 that exhibit a Th1 phenotype have been isolated from NOD mice using a similar immunization protocol as used here (16), but the in vivo biological effects of these cells has not been reported. Recently, Schloot et al. reported the generation of several GAD65 peptide-reactive cloned $\mathrm{T}$ cell lines as well (31). None of these T cells, however, accelerated or adoptively transferred diabetes (31). Nevertheless, this report clearly establishes that GAD-reactive $T$ cells have the potential to be diabetogenic. It should be emphasized that this phenomenon may not be restricted to GAD. It is possible that the activation of Th1 cells specific for other beta cell antigens may also evoke an isletdirected autoimmune response.

\section{Acknowledgments}

We thank Margaret Butler, David Liu, and Melissa Huang for assistance in the preparation of affinity purified GAD, Ronald Dirkx for immunohistochemistry, Dr. Hayday for his help in generating the E8 cells, and Dr. C.A. Janeway for providing us with reagents.

This work was supported by grants from the Juvenile Diabetes Foundation International (JDFI) and the National Institute of Diabetes and Digestive and Kidney Diseases (DK45735 and DK43078) and a gift from Camp NYDA. D. Zekzer is supported by a Mentor Grant from the American Diabetes Association. S. Wong and M. Solimena are the recipients of JDFI Career Development Awards.

\section{References}

1. Bendelac, A., C. Carnaud, C. Boitard, and J.F. Bach. 1987. Syngeneic transfer of autoimmune diabetes from diabetic NOD mice to healthy neonates. Requirement for both L3T4+ and Lyt-2+ T cells. J. Exp. Med. 166:823-832.

2. Miller, B.J., M.C. Appel, J.J. O'Neil, and L.S. Wicker. 1988. Both the Lyt-2 + and L3T4+ T cell subsets are required for the transfer of diabetes in nonobese diabetic mice. J. Immunol. 140:52-58.

3. Reich., E.P., R.S. Sherwin, O. Kanagawa, and C.A. Janeway. 1989. An explanation for the protective effect of the MHC class II I-E molecule in murine diabetes. Nature. 341:326-328.

4. Rohane, P.W., A. Shimada, D.T. Kim, C.T. Edwards, B. Charlton, L.D. Shultz, and C.G. Fathman. 1995. Islet-infiltrating lymphocytes from prediabetic NOD mice rapidly transfer diabetes to NOD-scid/scid mice. Diabetes. 44:550554.

5. Daniel, D., and D.R. Wegmann. 1996. Protection of nonobese diabetic 
mice from diabetic by intranasal or subcutaneous administration of insulin peptide B-(9-23). Proc. Natl. Acad. Sci. USA. 93:956-960.

6. Elias, D., T. Reshef, O.S. Birk, R. van der Zee, M.D. Walker, and I.R. Chen. 1991. Vaccination against autoimmune mouse diabetes with a T-cell epitope of the human 65-kDa heat shock protein. Proc. Natl. Acad. Sci. USA. 88:3088-3091.

7. Peterson, J.D., and K. Haskins. 1996. Transfer of diabetes in the NODscid mouse by CD4 T-cells clones. Diabetes. 45:328-336.

8. Wong, F.S., I. Visintin, L. Wen, R.A. Flavell, and C.A. Janeway, Jr. 1996. CD8 T cell clones from young nonobese diabetic (NOD) islets can transfer rapid onset of diabetes in NOD mice in the absence of CD4 cells. J. Exp. Med. 183:67-76.

9. Baekkeskov, S., H.-J. Aanstoot, S. Christgau, A. Reetz, M. Solimena, M. Cascalho, F. Folli, H. Richeter-Olesen, and P. De Camilli. 1990. Identification of the 64-kd autoantigen in insulin-dependent diabetes as the GABA-synthesizing enzyme glutamic acid decarboxylase. Nature. 347:151-166.

10. Baekkeskov, S., J.H. Nielsen, B. Marner, T. Bilde, J. Ludvigsson, and A. Lernmark. 1982. Autoantibodies in newly diagnosed diabetic children immunoprecipitate specific human islet cell proteins. Nature. 298:167-169.

11. Harrison, L.C., M.C. Honeyman, and H.J. DeAizpurura. 1993. Inverse relationship between humoral and cellular immunity to glutamic acid decarboxylase in subjects at risk of insulin-dependent diabetes. Lancet. 341:1365-1369.

12. Kaufman, D.L., M. Clare-Salzler, J. Tian, T. Forsthuber, G.S.T. Ting, P. Robinson, M.A. Atkinson, E.E. Sercarz, A.J. Tobin, and P.V. Lehmann. 1993. Spontaneous loss of T-cell tolerance to glutamic acid decarboxylase in murine insulin-dependant diabetes. Nature. 366:69-72.

13. Tisch, R., X.D Yang, S.M. Singer, R.S. Liblau, L. Fugger, and H.O. McDevitt. 1993. Immune response to glutamic acid decarboxylase correlates with insulitis in nonobese diabetic mice. Nature. 366:72-75.

14. Tian, J.M., A. Atkinson, M.C. Salzler, A. Herschenfeld, T. Forsthuber, P.V. Lehmann, and D.L. Kaufman. 1996. Nasal administration of glutamate decarboxylase (GAD65) peptides induces Th2 responses and prevents murine insulin-dependent diabetes. J. Exp. Med. 183:1561-1567.

15. Butler, M.H., M. Solimena, R. Dirkx, Jr., A. Hayday, and P. De Camilli. 1993. Identification of a dominant epitope of glutamic acid decarboxylase (GAD)65 recognized by autoantibodies in stiff-man syndrome. J. Exp. Med. 178:2097-2106.

16. Dirkx, R., Jr., A. Thomas, L. Li, A. Lernmark, R.S. Sherwin, P. De Camilli, and M. Solimena. 1995. Targeting of the 67-kDa isoform of glutamic acid decarboxylase to intracellular organelles is mediated by its interaction with the NH2-terminal region of the $65-\mathrm{kDa}$ isoform of glutamic acid decarboxylase. J. Biol. Chem. 270:2241-2246.

17. Matsuba, H., T. Jitsukawa, N. Yamagata, S. Uchida, and H. Watanabe. 1994. Establishment of rat glutamic acid decarboxylase (GAD)-reactive T-cell clones from NOD mice. Immunol. Lett. 42:101-103.

18. Solimena, M., D. Aggujaro, C. Muntzel, R. Dirkx, M. Butler, P. De Camilli, and A. Hayday. 1993. Association of GAD-65, but not of GAD-67, with the Golgi complex of transfected Chinese hamster ovary cells mediated by the N-terminal region. Proc. Natl. Acad. Sci. USA. 90:3073-3077.

19. Reiner, S.L., S. Zheng, D.B. Corry, and R.M. Locksley. 1993. Constructing polycompetitor cDNAs for quantitative PCR. J. Immunol. Methods. 165 37-46 (published errata in J. Immunol. Methods. 1994. 173:133 and 1994. 175: 275).

20. Wang, X.M., P.I. Terasaki, G.W. Rankin, Jr., D. Chia, H.P. Zhong, and S. Hardy. 1993. A new microcellular cytotoxicity test based on calcein AM release. Hum. Immunol. 37:264-270.

21. Lichtenfeld, R., W.E. Biddison, H. Schulz, A.B. Vogt, and R. Martin. 1994. CARE-LESS (calcein-release-assay), an improved fluorescence-based test system to measure cytotoxic T lymphocyte activity. J. Immunol. Methods. 172:227-239.

22. Braut-Boucher, F., J. Pichon, P. Rat, M. Adolphe, M. Aubery, and J. Font. 1995. A non-isotopic, highly sensitive, fluorimetric, cell-cell adhesion microplate assay using calcein AM-labeled lymphocytes. J. Immunol. Methods. 178:41-51.

23. De Camilli, P., R. Cameron, and P. Greengard. 1983. Synapsin I (protein I), a nerve terminal-specific phosphoprotein. I. Its general distribution in synapses of the central and peripheral nervous system demonstrated by immunofluorescence in frozen and plastic sections. J. Cell. Biol. 96:1337-1354.

24. Solimena, M., R. Dirkx, J.M. Hermel, S. Pleasic-Williams, J.A. Shapiro, L. Caron, and D.U. Rabin. 1996. ICA 512, an autoantigen of type I diabetes, is an intrinsic membrane protein of neurosecretory granules. EMBO (Eur. Mol. Biol. Organ.) J. 15:2102-2114.

25. Tian, J., M.C. Salzler, A. Herschenfeld, B. Middleton, D. Newman, R. Mueller, S. Arita, C. Evans, M. Atkinson, Y. Mullen, et al. 1996. Modulating autoimmune responses to GAD inhibits disease progression and prolongs islet graft survival in diabetes-prone mice. Nat. Med. 2:1348-1353.

26. Blanas, E., J.F. Allison, A.P. Miller, and W.R. Heath. 1996. Induction of autoimmune diabetes by oral administration of autoantigen. Science. 274:17071709

27. Signore, A., P. Pozzilli, E.A. Gale, D. Andreani, and P.C. Beverley. 1989. The natural history of lymphocyte subsets infiltrating the pancreas of NOD. Diabetologia. 32:282-289.

28. McInerney, M.F., S. Rath, and C.A. Janeway, Jr. 1991. Exclusive expression of MHC class II proteins on CD45+ cells in pancreatic islets of NOD mice. Diabetes. 40:648-651.

29. Kurrer, M.O., S.V. Pakala, H. Hanson, and J.D. Katz. 1997. Beta cell apoptosis in T-cell mediated autoimmune diabetes. Proc. Natl. Acad. Sci. USA. 94 213-218.

30. Yamada, K., N. Takane-Gyotoku, X. Yuan, F. Ichikawa, C. Inada, and K. Nonaka. 1996. Mouse islet cell lysis mediated by interleukin-1-induced Fas. Diabetologia. 39:1306-1312.

31. Schloot, N.C., D. Daniel, M. Norbury-Glaser, and D.R. Wegmann. 1996. Peripheral T cell clones from NOD mice specific for GAD65 peptides: lack of islet responsiveness or diabetogenicity. J. Autoimmun. 9:357-363. 